\title{
How Fashionable Are We? Validating the Fashion Interest Scale through Multivariate Statistics
}

\author{
Sabine Weber ${ }^{1}$ and Olaf Weber ${ }^{2, *(D)}$ \\ 1 School of Fashion, Seneca College, Toronto, ON M2J 2X5, Canada; sabine.weber@senecacollege.ca \\ 2 School of Environment, Enterprise and Development (SEED), University of Waterloo, \\ Waterloo, ON N2L 3G1, Canada \\ * Correspondence: oweber@uwaterloo.ca
}

Citation: Weber, S.; Weber, O. How Fashionable Are We? Validating the Fashion Interest Scale through Multivariate Statistics. Sustainability 2022, 14, 1946. https://doi.org/ $10.3390 /$ su14041946

Academic Editor: Andrea Pérez

Received: 23 December 2021

Accepted: 7 February 2022

Published: 9 February 2022

Publisher's Note: MDPI stays neutral with regard to jurisdictional claims in published maps and institutional affiliations.

Copyright: (C) 2022 by the authors. Licensee MDPI, Basel, Switzerland. This article is an open access article distributed under the terms and conditions of the Creative Commons Attribution (CC BY) license (https:// creativecommons.org/licenses/by/ $4.0 /)$.

\begin{abstract}
A person's fashion interest describes how familiar a person is with fashion. There are major differences among consumers in terms of fashion interest that can be used as a segmentation criterion for markets. Understanding the drivers of clothing consumption can be used to develop strategies to address consumption habits, including overconsumption. Consequently, many studies have developed questionnaires and interview guidelines to define fashion interest or other fashionrelated attitudes and behaviors. However, there is a gap in research about validating fashion scales. This study validates a fashion interest scale by comparing a random sample with a control group of fashion students, demonstrating differentiation between groups. We used principal component analysis (PCA) to explore the scale's homogeneity and $t$-tests and analysis of variance (ANOVA) to validate the scale. The results suggest that the scale is homogeneous and has high validity. We conclude that the scale can be used as a tool to segment markets to gain faster and higher quality data and as a benchmark for other studies.
\end{abstract}

Keywords: fashion; clothes; market segmentation; fashion interest scale; shopping behavior; fashion orientation; fashion involvement; attitude and behavior

\section{Introduction}

The global fashion industry accounts for up to two percent of the world's Gross Domestic Product (GDP) and four percent of the worldwide consumer expenditures [1] Likewise, the fashion industry has grown at 5.5 percent annually over the past decade, making it a vital economic factor [2]. Aside from fashion's strong economic value, it also fulfils significant social and personal functions and meaning in people's lives.

Because of the fashion industry's growth, there is a global call to increase its sustainability and tackle fashion's "overconsumption" problem [3]. The first step to address this issue is determining whether overconsumption results from consumer interest in purchasing fashion or clothes. Gwozdz, Steensen Nielsen [4] confirm that changing consumers' fashion purchasing behavior requires understanding their consumption patterns, including phenomena such as conspicuous consumption that appears when consumers want to enhance their prestige in society through the ownership of luxury fashion [5-7]. However, they do not address the difference between fashion and clothes and overlook the different functions they fulfil and how these functions determine how consumers choose products.

This conflation in terms can be seen in scholarship about fashion consumption more broadly. The term fashion is often erroneously used to describe all forms of clothing and accessories without any connection to their fashionable status [8]. As a result, the different functions of fashion and clothes and the motivations why they are purchased blend together. Differentiating between the terms clothing and fashion is critical to adequately address why people buy garments. This research addresses this lack of differentiation to show that fashion consumption is based on fashion and clothing consumption. We argue that the 
distinction between clothing and fashion is important to maintain and that many global consumer markets consist of many customers not interested in fashion but clothes.

Fletcher distinguishes between fashion and clothes by noting that "clothing is material production, [while] fashion is symbolic production" [9], p. 119. The term fashion typically describes the prevailing style of dress [10]. A fashion trend starts through mimicry or the refusal of a particular style or set of product characteristics within a consumer group [11]. By adopting a specific clothing style, people express that they identify themselves with the attitude and behaviour of a particular group they want to be part of. Changes in attitudes and behaviours become changes in fashion style; therefore, changes in styles are a key attribute for fashion [12]. Clothes also change over time due to the seasons, new production technologies, or a continuing routine of replacement; however, they are not socially negotiated in the way that fashion is. Their primary function is protection from the elements.

Ajzen [13] describes how thinking and feeling about something is expressed in a person's attitude and behaviour. A person with a high fashion interest will most likely look for fashionable garments, while a person with low fashion interest will not. The purpose of this research is to explore the difference between clothes and fashion and to determine how to evaluate whether a person is motivated to purchase a garment by an interest in fashion or clothes. This differentiation will help to understand better the drivers of clothing consumption, which can be used to develop strategies to address consumption habits, including overconsumption.

The following example shows how customers acknowledge different product attributes depending on what they want to purchase. For a customer interested in fashion, the clothing style reflects the newest trend and social acceptance, with little or no concern for whether the garment is durable and long-lasting because once the fashion trend is passed, the customer will change the style anyway. This is also the case if the garment is bought to satisfy conspicuous consumption because a passed fashion trend does not indicate status [7]. On the other hand, a person uninterested in fashion purchases a garment not because it is fashionable but because of qualities such as timelessness, functionality, practicability, and durability. Therefore, increasing the durability of garments to make it longer-lasting, might lead to less clothing consumption, but not necessarily to less fashion consumption.

Reducing fashion consumption requires knowledge about how customers satisfy their desire to change fashion styles constantly. Addressing customers' different wants and needs depending on their interest in fashion offers the possibility to reduce consumption through new business models such as garment rental and leasing, or clothing libraries. Secondhand fashion retail has been identified as one of the major strategies in sustainable fashion [14]. It addresses mainly fashion interested consumers who strive for a more sustainable fashion consumption [15]. However, before such strategies can be developed and proved, it is necessary to have a tool to determine the fashion interest. While Gwozdz, Steensen Nielsen [4] confirm that not all consumer segments support new business models, it remains unclear to which degree such services are dependent on customers' fashion interest.

A validated fashion scale is needed that assesses the fashion interest of a person or a market. For instance, the Ellen MacArthur Foundation [16] claims that more research is required to increase sustainability in the fashion industry that segments a market according to its fashion attitude and behavior. This article develops such a validated fashion scale. The scale is useful as a tool to determine the fashion interest of a person or a market. Such a market segmentation can be combined with other segmentation criteria and provide insights about consumer purchasing motivations.

Research has used different psychographic attributes of fashion to segment customers according to their fashion attitude and behavior. Questionnaires have been developed to assess a person's fashion interest [17], fashion involvement [18] that has also been connected with secondhand fashion consumption [19], trend sensitivity [20], or fashion orientation [21]. While numerous studies have developed questionnaires, none have focused on the validation of their questionnaires. Consequently, whether these questionnaires are 
suited to determine fashion interest, fashion involvement, trend sensitivity, and fashion orientation remains unclear. The presented study addresses this research gap.

To add to the knowledge about measuring fashion interest, the objective of this study is to analyze the validity of the fashion scale developed by [17] that evaluated fashion interest and demonstrated how the scale can be used to segment a market. Our research questions are whether the fashion interest scale of a representative sample of the Province of Ontario is normally distributed, and whether the fashion interest scale can discriminate between people with high and low fashion interest.

Based on the method of differentiation between known groups [22], we validate the fashion scale that measures a person's fashion interest and shopping frequency developed by [17] and compare their sample from the Province of Ontario (Canada) with a group of fashion students from Toronto (Ontario).

The results indicate that the questionnaire developed by [17] is suited to determining a person's fashion interest. All survey questions of the fashion scale show a high homogeneity and are valid for both groups. Therefore, the fashion scale is suited to assess fashion interest.

We conclude that the fashion scale is a valid instrument to segment markets according to fashion interest. The segmentation is useful for many applications in research and practices, such as consumption analyses and product development.

The remainder of the paper is structured as follows: First, we present a literature review on the difference between fashion and clothes to understand better what fashion is before we describe the meaning of fashion interest and how it is used as a segmentation criterion for markets. After presenting the research objective, we describe the methods and the results of the study. We conclude with a discussion of the results and implications of this research.

\section{Background}

The term fashion is used to describe the prevailing style of dress [10] or, as Kaiser puts it: "Fashion change is intricately linked to changing ideas about aesthetic rules" [23], p. 231. Wilson [12] further describes fashion as a permanent changing phantasmagoria of styles. Therefore, fashion starts with introducing a new style or a variation of an existing style [24]. Changes in detail can differ from one community to another and over time. Therefore fashion is change [10,12]. Wilson further claims that "no clothes are outside fashion .... Even uniforms have been designed [underlying fashion trends]" [12], p. 3. Loschek [8] distinguishes fashion from clothes by defining fashion as social validity and communication within society. She claims that "change [in clothing] is generated by the economic concept of seasonal renewal in clothing, without this renewal necessarily being accepted by the consumers or a fundamentally new image of fashion being created" [8], p. 134. Even seasonal changes in clothing do not represent changes in fashion since they are part of a continuing routine of replacing clothes. Von Busch further explains fashion is like language: "we cannot have our own personal language; it has somehow to be shared to work as communication" [25], p. 16. Hence, fashion is created and disseminated by groups or society at large by negotiating the limits of toleration, refusal, and acceptance of styles. Clothes, by contrast, are not socially mediated but can nonetheless become fashion through mimicry of style by a group in society [8]. The social validity makes it possible that fashion can occur when designers present their creations on a catwalk. Still, it can also occur when a teenager modifies jeans or shirts and peers copy the style. Fashion is not a top-down hierarchy of communication from the designer or industry to the public via the catwalk or weekly changing clothing styles in a store.

Fashion serves a cultural function, adding to the "traditions, and habits that are particular to a social group ... at a particular stage or state of civilisation" [10], p. 3. There can be multiple groups with different cultures and even subcultures, each of them describing "a distinctive network of behavior, beliefs, and attitudes" [10], p. 7. Similarly, Frings states that fashion reflects the social, political, economic, and artistic forces during a specific time [26], p. 4. Keiser and Garner see fashion as "a mirror of the prevailing ideas in 
our society" [11], p. 580 and, more broadly, a "consensus" of how we define and continually redefine ourselves [10], pp. 2-3. People seek fashion that caters to various subcultures and still offers opportunities for individual expression. Fashion, therefore, requires different styles of garments to satisfy people's needs.

While the choices of garments reveal the wearer's identity and what they think about themselves, these choices reflect who the wearer is and what the wearer does. Our garments are a means to express individuality and group belonging. Baumgartner [27], p. XV further describes, "Our clothing is the physical representation of our perceptions, our dissatisfactions, and our desires". Corner [28], p. 4, goes even further, claiming that clothing not only reflects "who we are ... [but] who we want to be". People have such a strong desire to use clothing to express their identity that they do so even when forbidden, such as during the Cultural Revolution in China when citizens were allowed to wear only one style of shirt but added distinctive collars [29].

While people use fashion to define their identity and distinguish themselves from others, they also want to be part of a group. González and Bovone [30] refer to this group identification as "respond[ing] to a psychological need for group linkage and personal self-assertion" [30], p. 99. Driven by the need to belong, individuals match their fashion with that of the group to show belonging. This desire means that if a group requires a specific dress style, people will buy it. Therefore, specific groups such as students at a particular age, or soccer fans watching a game, will most likely wear similar garments. "The paradox of fashion is that in trying to look distinctive, we model ourselves on others and give the impression of uniformity" [10], p. 3. To maintain what Loschek refers to as "a uniform image" [8], people belonging to a specific group share their interest in fashion and shopping behavior and buy garments to match their group. Hence, fashion interest can be used to segment a market according to people's attitudes and behavior about fashion.

Fashion interest describes how familiar a person is with fashion and how much the person knows about fashion. Fashion knowledge is included in a consumer through "product experiences, ad exposure, interactions with salespeople, friends or the media, previous decision-making or previous consumption and usage experiences held in memory" [18], p. 875. Unsurprisingly, many of these sources are related to fashion consumption because the more fashion a customer consumes, the more knowledge the consumer gains about fashion. People can express their fashion interest by showing their trend sensitivity and whether they want to take on a fashion leadership role and become a trendsetter. Fashion trend sensitivity and fashion leadership influence a person's shopping behavior. Higher fashion interest, however, does not have to be unsustainable. Some studies, for instance, found that fashion interested consumers are also often consumers in the secondhand [15] and vintage market [19] that increase the lifespan of a garment [14].

A person's fashion trend sensitivity reflects how fast the person adopts a new trend. The theory of trend adaptation goes back to Rogers' diffusion of innovations model, a model used in over 5000 studies [18]. This theory of trend adaptation reflects an adaptation pattern of a normal distribution and is generally accepted among researchers as a theory to explain how different consumer segments adopt trends over a given time frame [18]. The theory models how each market segment influences the attitudes of the next segment [31].

According to Rogers [32], people can be innovators (also called trendsetters), fashion change agents (if they adopt trends early), or followers (if they require more time to recognize a trend before they adopt it). Fashion innovators, those with high fashion interest and the highest fashion trend sensitivity, are not only the first to adopt new fashion and trends but are also opinion leaders [24,31]. They are "influential" [33], p. 178, because they are "the first to broadcast the latest fashion styles, which influence others to buy new fashion items" [20], p. 707. While fashion leaders must cope with the risk that a particular style might not become fashion and ends up as a fad, many celebrities strive to be recognized as a fashion leader. Likewise, people surround themselves with glamourous images and products to cultivate extraordinary taste, identify as privileged, and share in their fantastical lifestyle [34]. However, fashion innovators will no longer wear the 
style once fashion followers adopt a fashion trend; this behaviour creates the bell curve adaptation pattern.

People with a high fashion interest want to wear the latest fashion. The higher a person's fashion interest, the more fashionable the person, and the more they use fashion to show their uniqueness [31]. Being a fashion leader requires enough affluent purchasing power to change style frequently and purchase trends early. They shop more often to look for new trends, or, as Tigert, Ring, and King put it, the "highly fashion involved consumer is also the heavy clothing fashion buyer" [35], p. 46. They buy new garments often, even if they do not need them, to keep their wardrobe up-to-date [3]. Likewise, they spend a reasonable amount of time following the fashion news to be informed about fashion trends. This knowledge, combined with personality factors, provides a customer with the confidence to make fast purchasing decisions [36].

Furthermore, customers with a high fashion interest buy fashion just when the trend comes out and are often impulsive. They buy more clothes than their friends and community and shop more frequently. Workman and Kidd [31] indicate that fashion innovators are in high need of uniqueness. Law, Zhang, and Leung [37] claim that there is a linear relationship between fashion trend sensitivity and fashion consumption, which means the more often fashion trends change, the more these customers shop. While fashion-oriented consumers often shop on impulse [31], impulse buying often leads to overspending [38]. Fashion interested innovators spend a relatively high proportion of their income on fashion [39]. Fashion innovators shop at retailers who lead fashion. Therefore, they prefer fashion specialty stores over traditional retailers or department stores [40]. In contrast, customers not interested in fashion often purchase clothing in the decline stages when products are discounted, and fashion customers no longer wear these items [40]. People differ significantly in how fashionable they are; hence, fashion interest can be used as a segmentation criterion to differentiate a market.

Markets can be divided into segments or groups with similar interests [41]. Cahill [42] further outlines how consumers are divided into different groups to deliver them the "right products". Fashion interest is a psychographic attribute that refers to attitudes and behavioral criteria based on similar interests, values, emotions, or fashion perceptions. Fashion interest describes a person's relationship with fashion and is a legitimate way to segment a market if we can identify the pertinent questions to determine a person's fashion interest.

Fashion interest can be used as a metric for segmenting consumer markets in regard to fashion. For example, Weber, Lynnes, and Young [43] relate fashion interest and fashion shopping behavior as a driver for clothing disposal. Bhatia examined the impact of fashion interest, materialism, and internet addiction on compulsive buying behavior of apparel [44]. Other studies have identified fashion interest as part of other market segmentation criteria. For example, Gam [21], p. 180 describes fashion orientation as "an individual's attitude toward, interest in, and opinions about fashion products". Gutman and Mills [45] describe fashion orientation as a factor composed of four dimensions: fashion leadership, fashion interest, the importance of being well dressed, and the disinterest in fashion or being a fashion leader-what they describe as having an anti-fashion attitude. Park and Burns [46] further explored the relationship between fashion orientation and buying practices. The researchers found that fashion interest significantly influenced compulsive buying and credit card use. In contrast, Matthews and Rothenberg [47] claim that a strong interest in fashion and consistency in following trends leads to fashion consciousness and, eventually, to fashion innovativeness in contrast to groups that resist innovation in fashion [36].

In the literature, the term "fashion interest" is close to fashion involvement but often used to segment markets [43,44,48,49], or as part of fashion orientation [21,45-47]. Fashion involvement describes the participation of an individual consumer in fashion. Since involvement often starts with interest, there is an overlap in the questions to determine fashion involvement and its expression. Joo Park, Young Kim [50] analyzed the relation- 
ships among fashion involvement, positive emotion, hedonic consumption tendency, and fashion-oriented impulse buying in the context of shopping. While [35] developed an index of fashion involvement, other researchers related fashion involvement with criteria such as the relationship between self-monitoring, materialism, buying behavior, and consumer characteristics [51], personal characteristics such as gender and age [18], and the motivation to purchase garments to achieve social status [5]. A comprehensive questionnaire to determine fashion interest was developed by Weber [52]. Respondents answered questions on a 5-point Likert scale, including fashion trend sensitivity, opinion leadership, and shopping behavior [52]. All questions were equally important and were assigned the same weight. The questionnaire from Weber [52] was based on research from Lang, Armstrong [20], who explored drivers of clothing disposal in the US based on personal attributes and behavior. The second basis is [35], who studied fashion involvement and buying behavior, and [53] used Rogers' diffusion of innovations model to connect fashion involvement and consumer innovation. Although there is extensive research on fashion interest as a segmentation criterion, there is no validated scale.

There is, therefore, a need for a validated questionnaire to determine a person's fashion interest. While most scholars developed questionnaires with similar questions, none of these studies validated their scale with a control group and focused on validating the questionnaire itself. There is a research gap for a validated scale to determine fashion interest. A valid questionnaire's advantage is to help collect better quality data with high comparability. Hence, a validated scale reduces the effort but increases data credibility.

This research aims to validate the fashion interest scale developed by [17] to find out if this questionnaire is suited to identify a person's fashion interest and to segment markets. Since the questionnaire from Weber is based on the questionnaire from $[20,39,54]$, it can be assumed that the theoretical background of the survey is well-founded in the literature and that the questionnaire has high content validity. Therefore, this research will focus on construct validity.

\section{Materials and Methods}

Scale validation is the third step in scale development, which includes testing a scale's reliability, validity, and homogeneity [22]. We analyze the reliability by applying the scale to the same sample again to test whether the scale measures the same in a repeated measurement. The validity can be tested by using the scale to differentiate between known groups [22]. The homogeneity can be analyzed using multivariate methods, such as factor analysis and Cronbach's alpha [55,56].

This study evaluated the fashion scale based on fashion interest and fashion shopping behavior developed by Weber [52] by adding a sample of fashion students as a control group. A principal component analysis is used to explore the homogeneity of the questions used to create the fashion scale [54]. A differentiation by known groups [22] is used to test the scale validity.

The original study by Weber [52] took a random sample from the Province of Ontario, Canada, to determine the fashion index. However, their scale was not normally distributed but skewed to the left. Hence, either people in Ontario have a low fashion interest, or the questions to determine a person's fashion index were not suited to describe fashion interest.

A fashion interested sample has been added to the Ontario random sample to analyze the scale's validity based on the differentiation between known groups. It consists of college fashion students. Fashion students are highly interested in fashion and should have a higher value in their fashion scale than the random sample participants from Ontario. During the winter semester of 2017, 268 students were contacted and encouraged to answer the questionnaire. A total of 228 students participated in the study, and all completed the questionnaire.

In line with Weber [52], this study used parametric statistical methods to evaluate the scale. A principal component analysis (PCA) was conducted to analyze the homogeneity of the scale. PCA analyses the loadings of the items on the first factor and the variance 
explanation through the first factor. In contrast to Cronbach's alpha [55], PCA is less vulnerable to a high number of items [54].

To test differences between the random sample and the student sample, we used $t$-tests to analyze differences between the random sample and the student sample. Furthermore, we used multi-factor analyses of variance (ANOVA) to examine the impact of more than one factor on the fashion scale. Finally, we used $\mathrm{Chi}^{2}$-tests to analyze categorical data.

\section{Results}

First, we compared the physical attributes of the total sample with the random Ontario sample and the student control group. The geo-demographic geographic criteria include gender, age range, marital status, years living in Canada, and income distribution.

The sample consists of 231 fashion students and 422 participants from a random sample in Ontario. Altogether, the total sample consists of 653 participants. Of those, 232 identified as male, 414 identified as female, and one indicated "others". When comparing the two samples with a Chi ${ }^{2}$ test, the Ontario sample consists of 51 percent female and 48 percent male. In contrast, the student sample had 87 percent female, 13 percent male, and one indicated "other". Therefore, the gender distribution of the Ontario sample reflects the gender distribution of the province of Ontario: 52 percent female and 48 percent male [57]. In contrast, the percentage of females is higher in the student sample.

Figure 1 shows an analysis of the age ranges in both samples. The Ontario sample is close to the Ontario population, except in the age range above 65 years, where the sample is 3\% lower than the numbers from Statistics Canada [57]. The student sample is younger than the random sample $\left(p<0.0001, \mathrm{Chi}^{2}=257.76\right)$. The age range is presented in Figure 1.

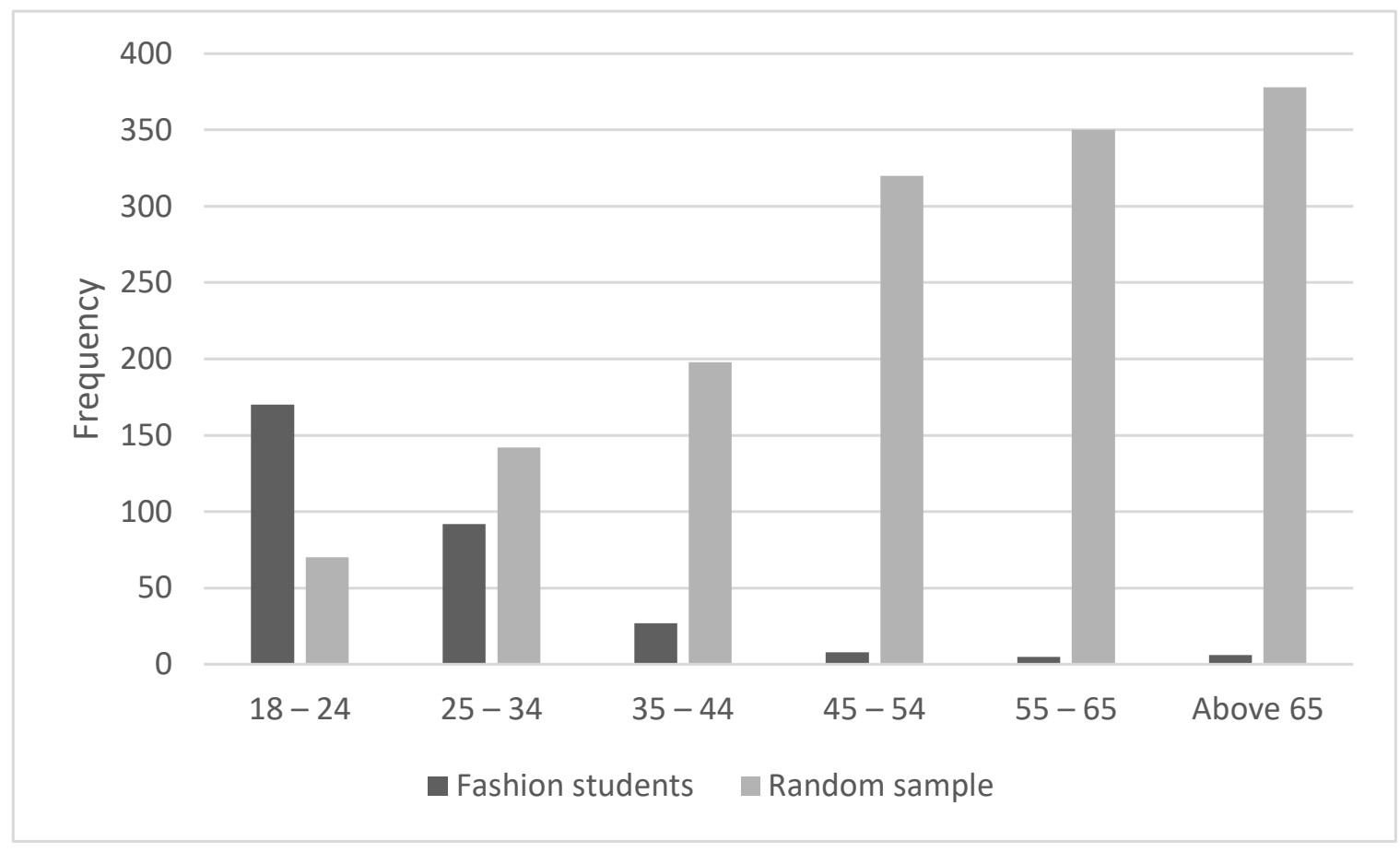

Figure 1. Distribution of the age groups.

Marital status was determined to describe the samples further. Out of 653 participants, 252 participants are single, 81 are single living with their parents, 150 live with their partner or are married, 120 live with their partners and children, and 25 indicated "other". Comparing the random Ontario sample and the students results in a statistically significant difference $\left(\mathrm{Chi}^{2}=163.3, p<0.001\right)$. Fashion students are more likely to be single and live with their parents than the random sample. 
Furthermore, the income distribution in the sample is presented in Figure 2. To compare the two samples, we conducted a $\mathrm{Chi}^{2}$ test. While the result suggests that the Ontario sample represented all income levels, the high-income levels above CAD 75,000 were about five times as high as Statistics Canada's. (The sample had 30.8 percent above an income of CAD 75,000 while the province has 5.6 percent $[52,58])$. $\mathrm{AChi}^{2}$ test indicates that the fashion students have a lower income than the random Ontario sample $(p<0.0001$, $\mathrm{Chi}^{2}=228.69$ ).

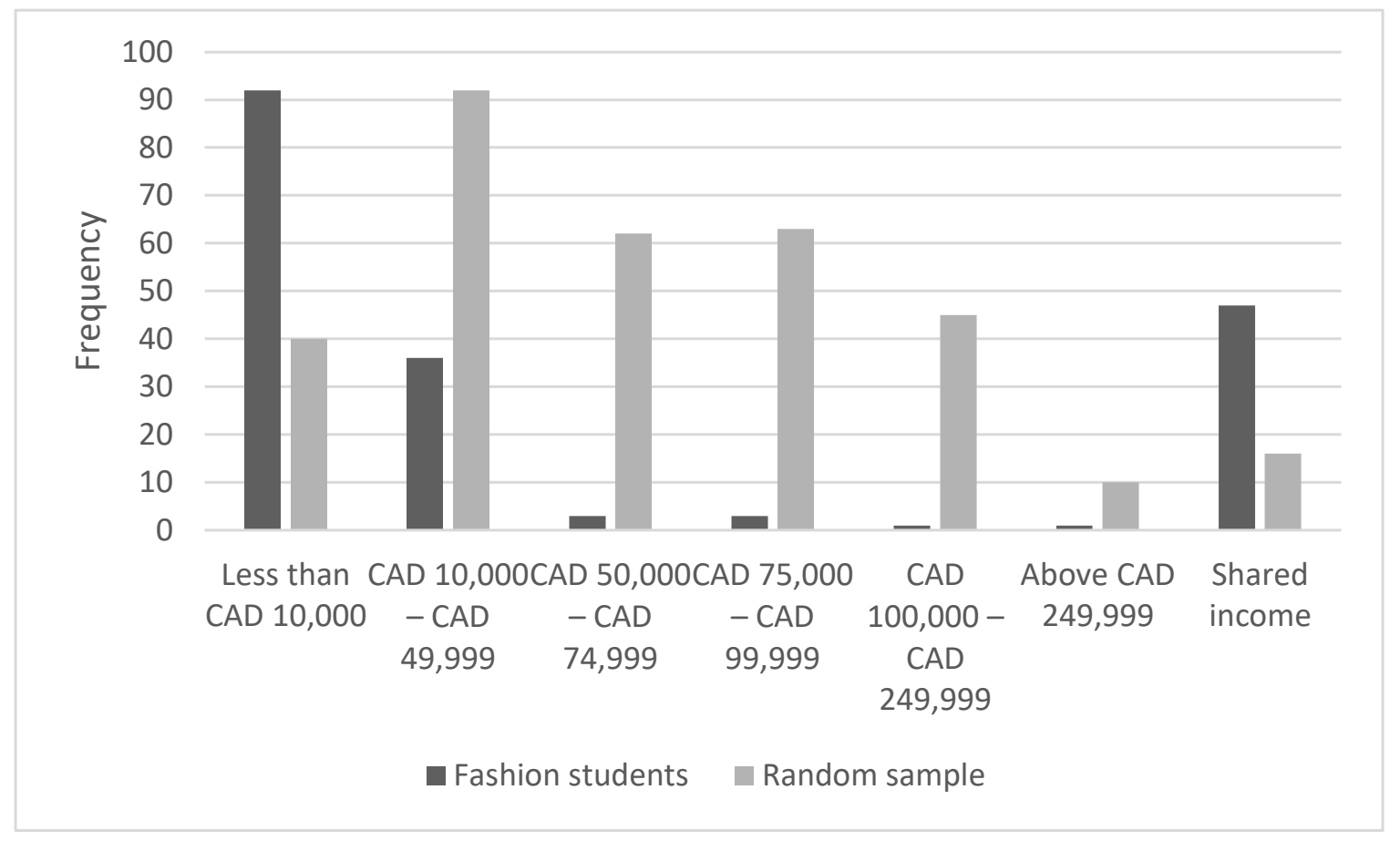

Figure 2. Annual income of fashion student and the random sample.

As the analyses above have shown, both samples are different in the demographic criteria, and there is more value in comparing the groups than looking at the total sample. Therefore, this section will mainly compare the samples regarding the psychographic attributes. We will start with the behavioral criteria-how often the participant shops-before looking at the participant's fashion interest.

The distribution of the question, "How often do you shop for clothes?" split by the random sample and the fashion students is presented in Figure 3.

The results show that compared to the random sample, nearly three times the number of students go shopping every or every other week. The highest percentage, 39\%, for the random sample was in the category "shop only once or twice a year", while more than half of the students, $63 \%$, shop at least once a month.

Before we can compare the sample in regards to fashion interest, we analyze the agreement with the questions whether the participants buy clothes often even if they do not need them $\left(\bar{x}_{\text {fashion }}=3.42 ; \bar{x}_{\text {random }}=2.66 ; p<0.0001\right)$, whether they are concerned if clothing is practical or timeless and can still be worn the following season $\left(\bar{x}_{\text {fashion }}=3.35\right.$; $\left.\bar{x}_{\text {random }}=3.13, p=0.015\right)$, and whether they purchase new clothing more often than their friends $\left(\bar{x}_{\text {fashion }}=3.32 ; \bar{x}_{\text {random }}=2.70 ; p<0.0001\right)$. The questions could be answered on a five-point Likert type scale with "strongly agree" (1) to "strongly disagree" (5). The $t$-tests for all three questions and the sample origin as an independent variable are significant. 


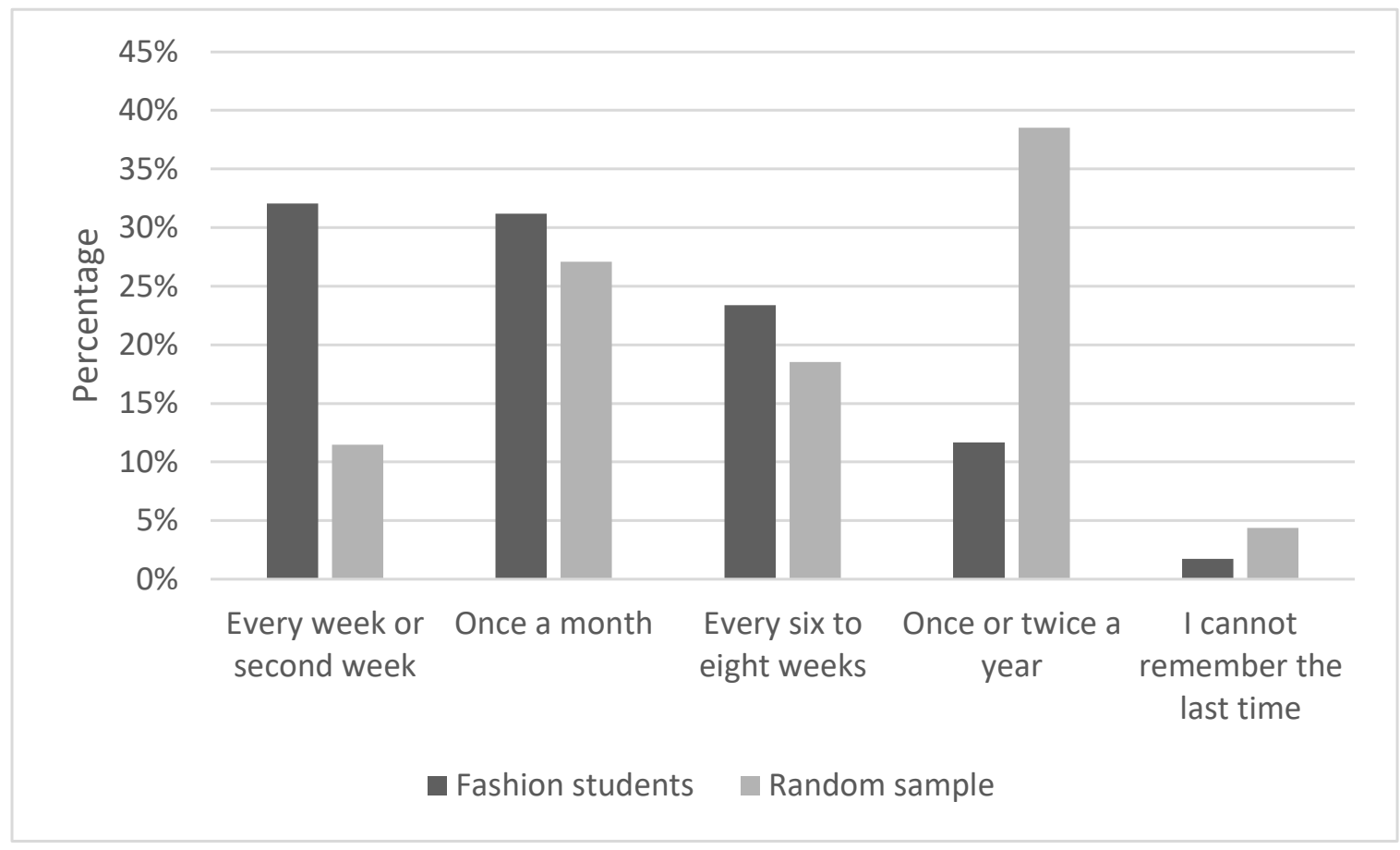

Figure 3. Percentage of the categories of the question "How often do you shop for clothes?" for fashion students and the random sample.

\subsection{Scale Homogeneity}

Next, we conducted a factor analysis to explore the homogeneity of the fashion scale. The first factor explains 94.98 percent of the total variance (Eigenvalue $=10.51$ ). The variance explanation of the second factor is 4.67 percent. Therefore, we can assume one main homogeneous factor. The loadings of the items on the first factor are higher than 74 percent, except the item "I am not concerned if clothing is practical or timeless and can still be worn in the next season" (see Table 1). The loading of this item is 0.34 . Because the loading on the first factor is still the highest, we calculated the fashion index using the sum of the scores for the 16 questions. The maximum value is 80 , indicating a high fashion index.

Table 1. Factor loadings.

\begin{tabular}{lc}
\hline Variable & Loading \\
\hline Q7_1: I seek out new fashion trends, and I spend a fairly high proportion of my income and time on fashion & 0.88 \\
Q7_2: I read the fashion news regularly and try to keep my wardrobe up-to-date with fashion trends & 0.84 \\
Q7_3: I usually try to be different from others by wearing fashionable clothing & 0.79 \\
Q7_4: I am interested in shopping at fashion specialty stores rather than department stores for my fashion needs & 0.78 \\
Q7_5: I am usually the first among my friends to buy the latest clothing styles & 0.89 \\
Q7_6: Compared to my friends, I own more of the latest fashion styles & 0.88 \\
Q8_1: I think I am a trendsetter and my clothes are very fashionable & 0.84 \\
Q8_2: I am usually the first to know the latest fashion trends & 0.87 \\
Q8_3: My friends regard me as a good source of fashion advice & 0.84 \\
Q8_4: I like to buy new clothing early, just when the fashion trend begins & 0.87 \\
Q8_5: I follow the fashion styles of celebrities, and I find they influence my fashion purchasing habits & 0.79 \\
Q8_6: I often influence the types of clothing styles my friends buy & 0.80 \\
Q8_7: I usually buy clothing because I am thrilled by a new fashion trend & 0.85 \\
Q10_1: I buy new clothing often, even if I don't need it & 0.75 \\
Q10_2: I am not concerned if clothing is practical or timeless and can still be worn in the next season & 0.34 \\
Q10_3: I purchase new clothing more often than my friends & 0.81 \\
\hline
\end{tabular}


In addition to the factor analysis, we analyzed the scale using Cronbach's alpha [55]. The analysis of the total sample resulted in $\alpha=0.97$. The random sample's value is $\alpha=0.97$, and $\alpha=0.90$ for the fashion students. All values suggest a high homogeneity of the scale.

\subsection{Differences in Fashion Interest}

The average for the different components of the fashion index split by the random sample and the fashion students is presented in Figure 4. The figure suggests a higher value for fashion students than for the random sample for every question.

Q10_3: I purchase new clothing more often than my friends

Q10_2: I am not concerned if clothing is practical or timeless, and can still be worn in the next season

Q10_1: I buy new clothing often, even if I don't need it

Q8_7: I usually buy clothing because I am thrilled by a new fashion trend

Q8_6: I often influence the types of clothing styles my friends buy

Q8_5: I follow the fashion styles of celebrities and I find they influence my fashion purchasing habits

Q8_4: I like to buy new clothing early, just when the fashion trend begins

Q8_3: My friends regard me as a good source of fashion advice

Q8_2: I am usually the first to know the latest fashion trends

Q8_1: I think I am a trendsetter and my clothes are very fashionable

Q7_6: Compared to my friends, I own more of the latest fashion styles

Q7_5: I am usually the first among my friends to buy the latest clothing styles

Q7_4: I am interested in shopping at fashion specialty stores rather than department stores

Q7_3: I usually try to be different from others by wearing fashionable clothing

Q 7_2: I read the fashion news regularly and try to keep my wardrobe up-to-date with fashion trends

Q7_1: I seek out new fashion trends and I spend a fairly

high proportion of my income and time on fashion

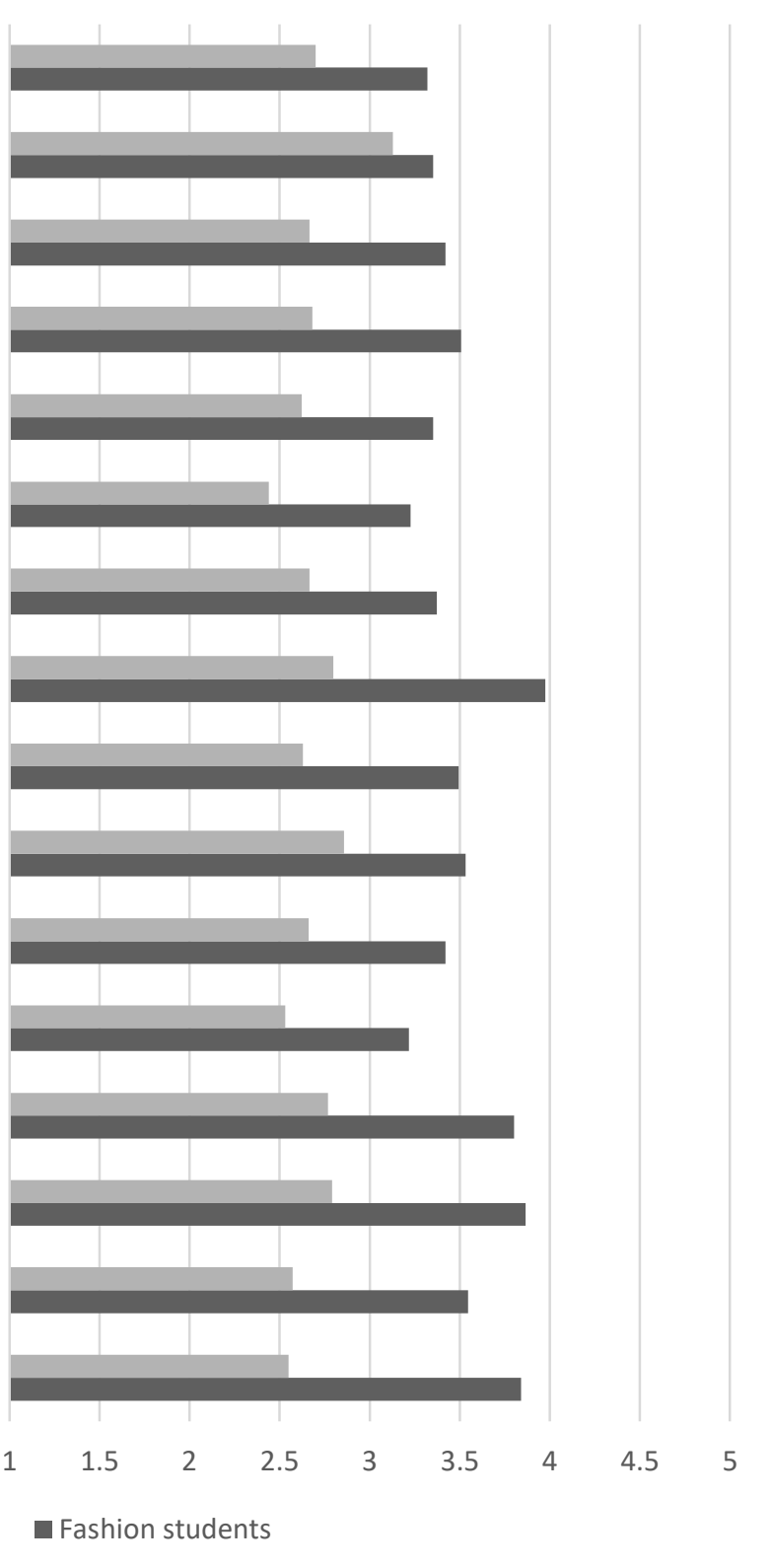

Random sample $\quad$ Fashion students

Figure 4. Item difference between the two samples.

We conducted a $t$-test to analyze differences between the fashion students and the random sample for individual items and the fashion scale. The values for the individual items as well as for the fashion scale are significantly higher for fashion students than for the random sample $(p<0.0001$ for all items and the fashion scale except Q10_2 $(p=0.015)$ ).

To analyze whether the differences are caused by other external variables that correlate with the group's origin, we calculated an ANOVA with the fashion index as dependent 
variable and gender, age group, income, and sample group as independent factors (see Table 2$)$. The model is significant $(p<0.0001)$ with $\mathrm{r}^{2}=0.35$. All variables have a significant effect on the fashion scale.

Table 2. ANOVA with fashion index, age group, income, and sample group (random sample vs. fashion students).

\begin{tabular}{cccc}
\hline Source & df & F & $p$ \\
\hline Model (all factors) & 16 & 18.76 & $<0.0001$ \\
Gender & 2 & 4.5 & 0.0115 \\
Age & 5 & 28.09 & $<0.0001$ \\
Income & 8 & 4.96 & $<0.0001$ \\
Sample & 1 & 13.67 & 0.0002 \\
\hline
\end{tabular}

First, female participants in the Ontario sample had an average fashion scale value of $\bar{x}=50.41$, while male participants scored at an average of $\bar{x}=43.25$. Male participants from the fashion school, however, had a significantly higher fashion score than their female counterparts $(p=0.0045, \mathrm{~F}=5.53, n=227)$, in contrast to men enrolled in non-fashion-related college programs [59].

Furthermore, we present the fashion scale results split by age group (see Figure 5). The results demonstrate that 18-25-year-old respondents have the highest fashion interest, followed by the 35-44-year-old range. There is a decreasing trend in fashion interest after 45 , and fashion interest is lowest after 65.

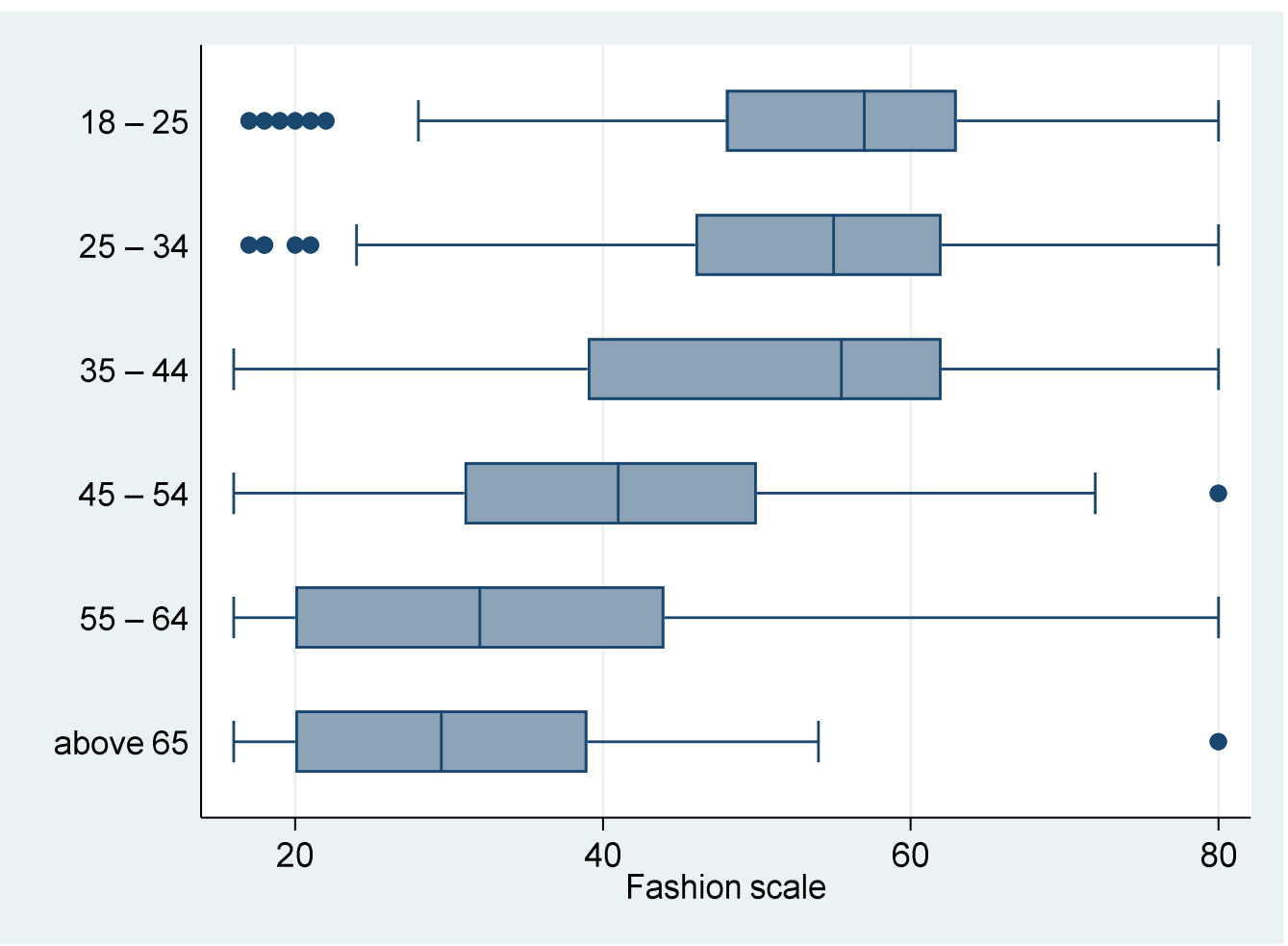

Figure 5. Fashion scale split by age group. Dots represent values above the 90th percentile and below the 10 th percentile.

A comparison of the fashion students and the random sample by age group is presented in Figure 6. Fashion students have a higher fashion interest than the random sample in all age groups. 


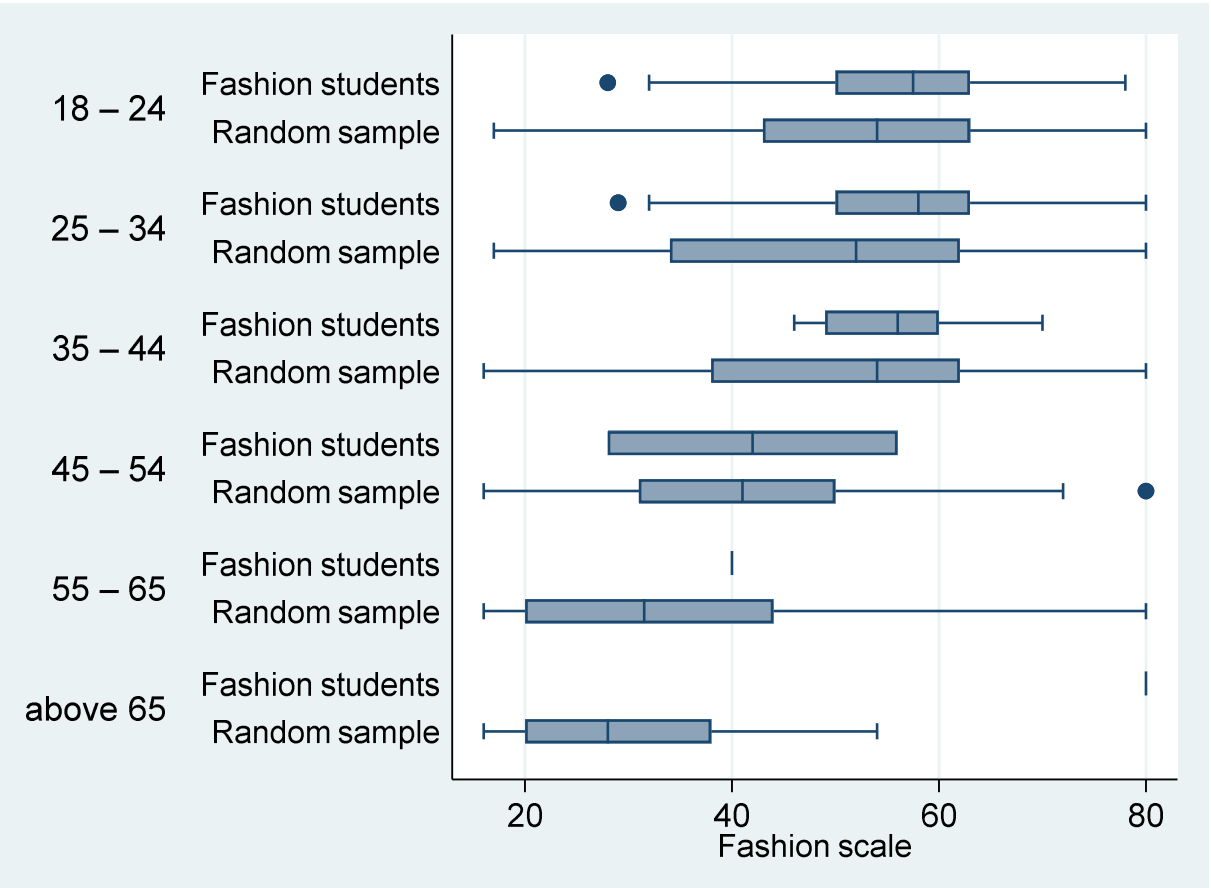

Figure 6. Fashion scale split by age group and sample. Dots represent values above the 90th percentile and below the 10th percentile.

The fashion scale distribution of the fashion students against the random sample is presented in Figure 7. The results suggest that the random sample is skewed to the right, while the fashion students' sample is skewed to the left and that fashion students have a higher index than the random sample.

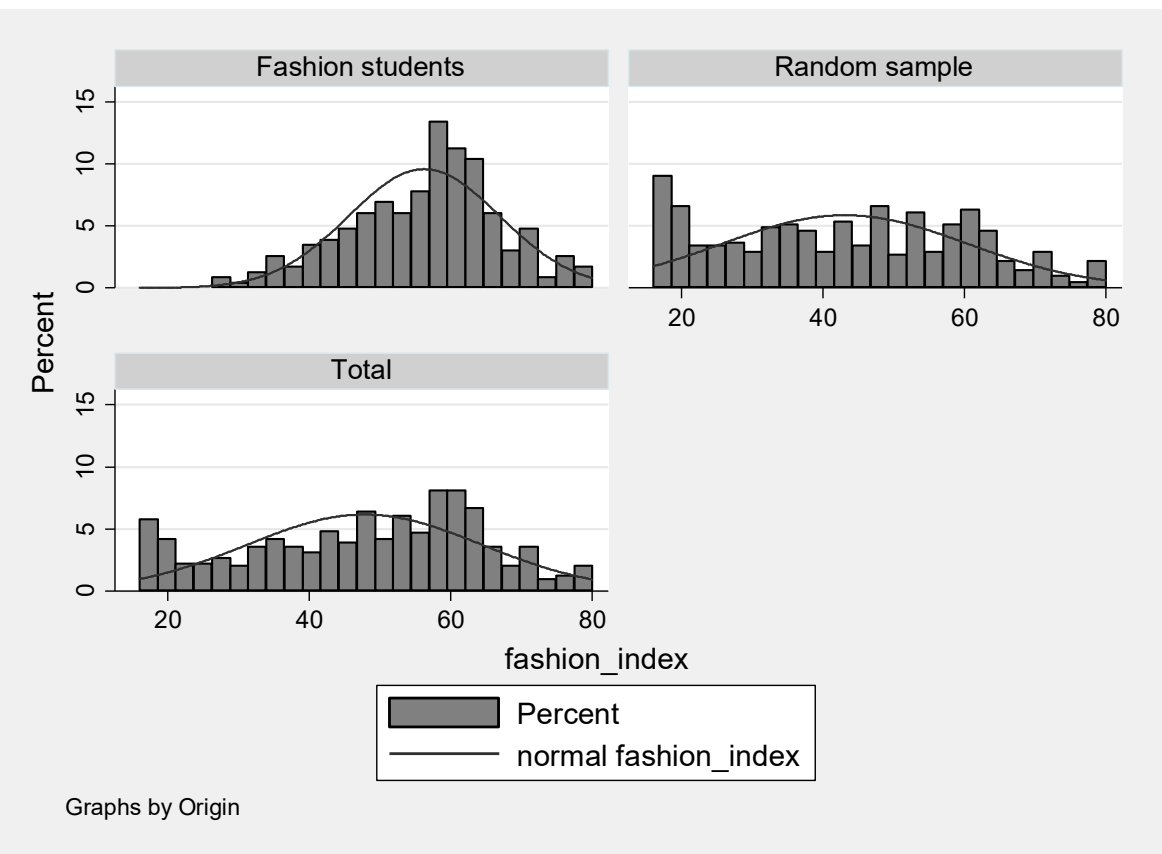

Figure 7. Percentage distribution of the two sample groups and for the whole sample with regard to the fashion index.

Furthermore, we present the box plots for the fashion index split by income (see Figure 8). The highest fashion index value can be found in the income group between CAD 
100,000-CAD 149,000. The results suggest that the fashion index is different for income groups but does not linearly increase with income.

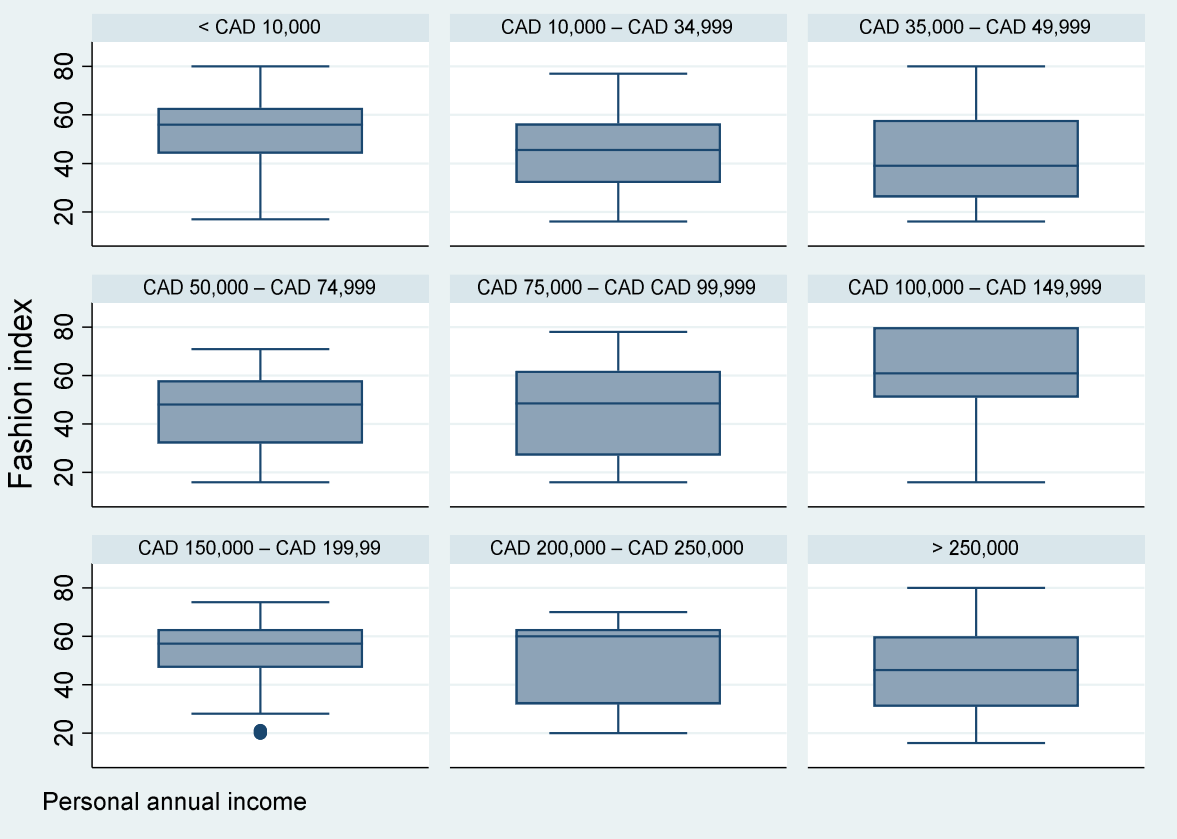

Figure 8. Box plots for the fashion index split by income. Dots represent values above the 90th percentile and below the 10th percentile.

Figure 9 presents the box plot divided by sample and income. It suggests that the students have a higher fashion index than the random Ontario sample in each income group. This result also explains that the fashion index does not increase with income. Usually, students do not have a high income, but they have higher values on the fashion index.

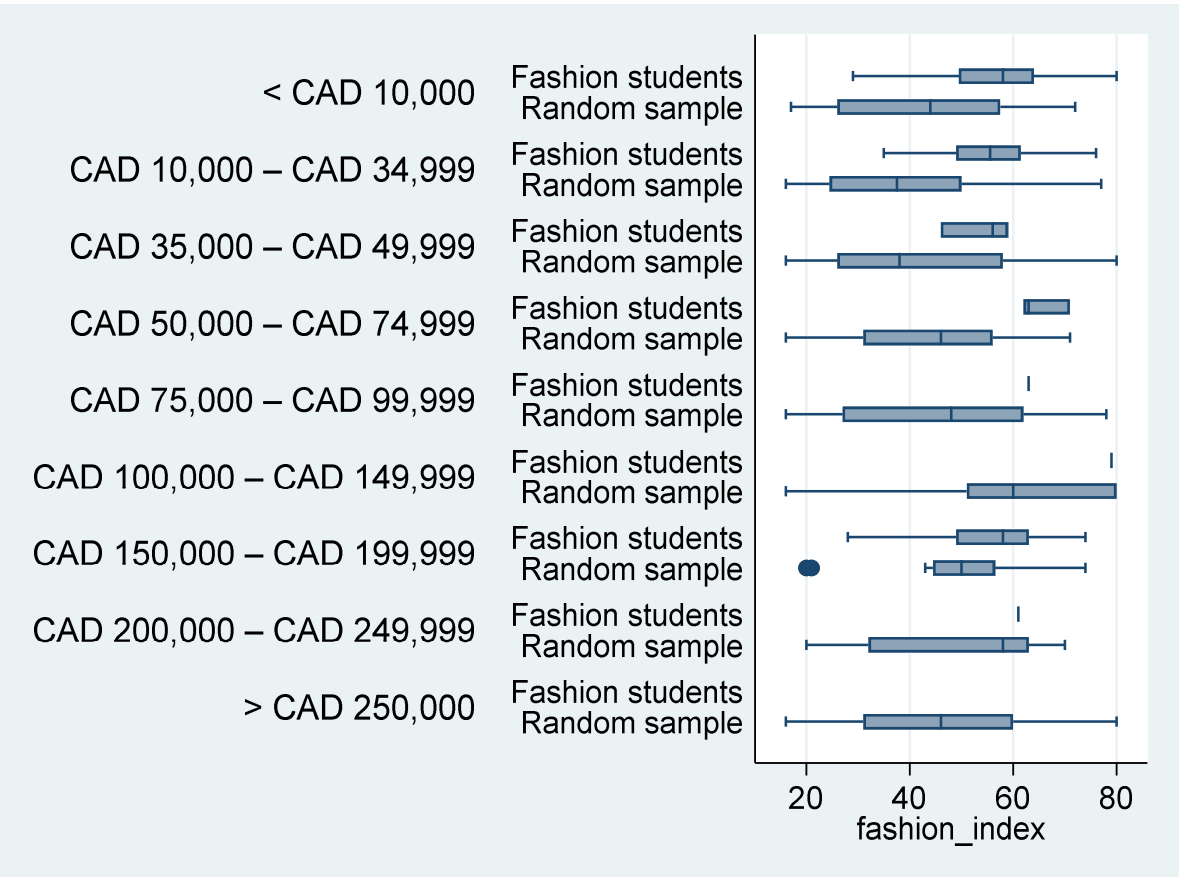

Figure 9. Box plots for the income group by the sample group. Dots represent values above the 90th percentile and below the 10th percentile. 


\subsection{Shopping Frequency and Fashion Scale}

We also tested differences in the fashion scale for high-frequency and low-frequency textile shoppers using an ANOVA, and when controlled for the sample group. The ANOVA is significant $\left(p<0.0001\right.$, adjusted $\left.r^{2}=0.58\right)$, and both the sample group and shopping frequency are significant ( $p<0.00001$ for both). The interaction between the two independent variables is also significant $(p<0.00001)$. The result is presented in Figure 10. It suggests that fashion students have higher values, but the shopping frequency and being a fashion student interact. While both groups are very similar in the fashion scale if they are high-frequency shoppers, they differ for low-frequency shoppers. Even if fashion students do not shop that often, they have higher fashion scale values than participants from the random sample.

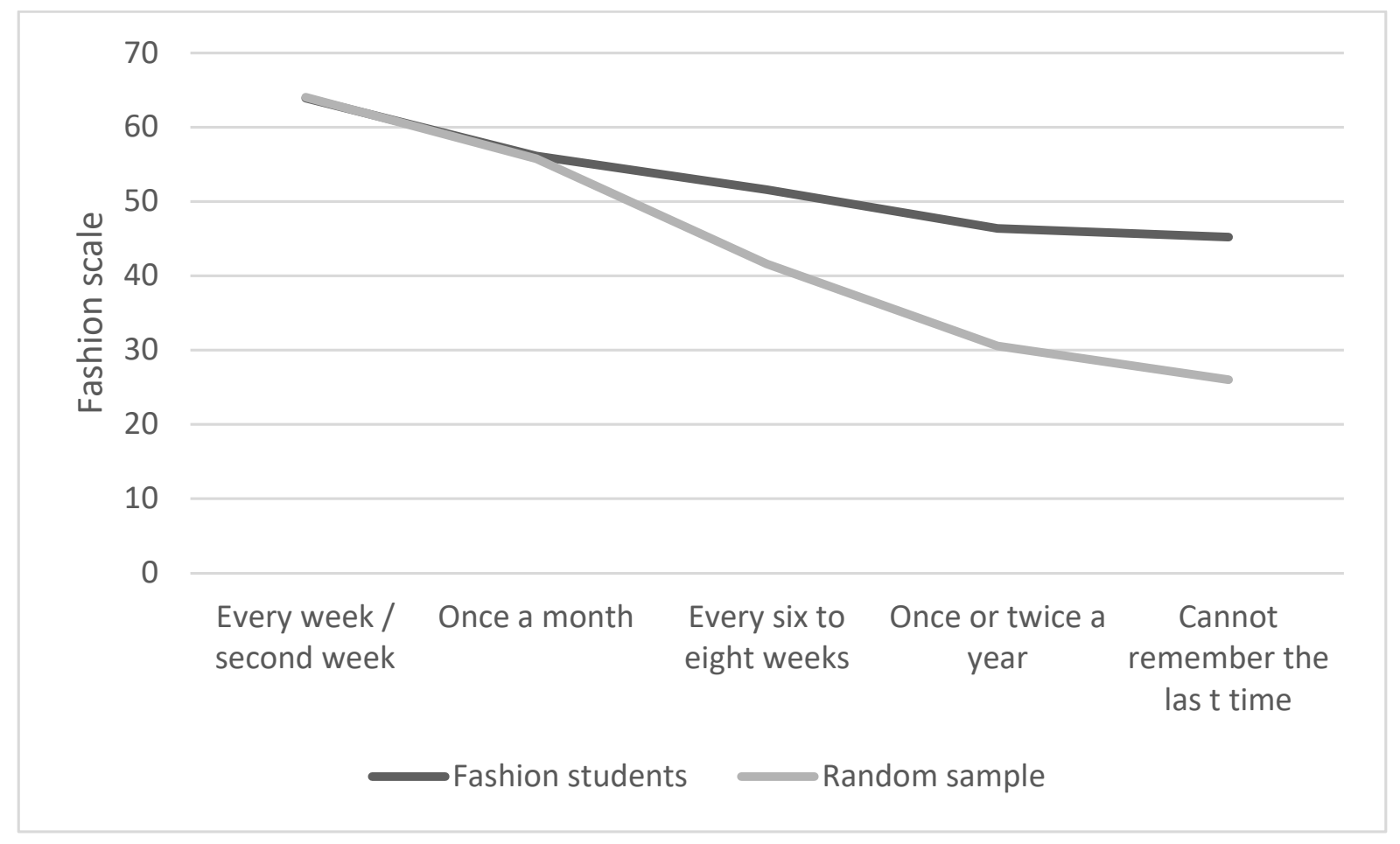

Figure 10. Shopping frequency and fashion scale for fashion students and the random sample.

\section{Discussion}

This research validates the fashion scale developed by Weber [52], which successfully differentiates established groups of high and low fashion interest. The results indicate that the questionnaire is suited to determine the fashion interest of a person because both samples had a significantly different fashion interest. The control group of fashion students, which had a higher percentage of females and was younger, confirmed the anticipated results of having a high fashion interest. This means the questionnaire truly measures what it intends to measure: fashion interest. A validated questionnaire that measures fashion interest offers a benchmark that can help other researchers use it as a criterion and combine it with other factors. Further studies that integrate fashion interest as a criterion will also deepen understanding about fashion interest and clothing consumption. For instance, the connection between conspicuous consumption of fashion [5-7] and fashion interest as well as the attractiveness of a secondhand and vintage market $[14,15,19]$ for consumers with high fashion interest can be analyzed.

We analyzed the reliability of the questionnaire by analyzing the homogeneity of the questions. The homogeneity analysis has shown that all sixteen survey questions of the fashion scale are homogeneous. This means all questions have a high consistency with fashion interest. None of the questions need to be discarded or revised. Furthermore, 
the homogeneity is valid for both sample groups. Consequently, the questions are strongly interrelated, and the questionnaire consists of a sufficient number of questions. Therefore, all items are suited to determine fashion interest, making the questionnaire highly reliable.

Moreover, the questionnaire by Weber included ten questions from the research conducted by [20], p. 711. Although the researchers did not provide the Cronbach's alpha value for each question, they displayed some values. However, only [20] analyzed the reliability of their scale to determine trend sensitivity using fifteen questions, with ten of these questions included in the research from [17]. The value for alpha in the Lang et al. study was 0.93 compared to 0.97 in the presented study. Similarly, [60] developed three questions to evaluate shopping frequency, from which Weber integrated two of them. The value for alpha was 0.86, while the study from Morgan and Birtwistle [53] combined consumer focus groups, consumer interviews, and a structured survey, and the survey results of the section fashion innovativeness had an alpha coefficient of 0.703 . However, the current study went further in analyzing the reliability and used principal component analysis (PCA). PCA is less vulnerable to the number of items and, therefore, more robust to assess the homogeneity of a scale that consists of a high number of questions. Though [35] also conducted a principal component analysis, their loading was lower than in our study.

Furthermore, they did not disclose the variance explanation of their scale. The present study demonstrates that the items in the first factor explain 94.85 percent of the variance. Consequently, this study contributes to the academic literature by providing a reliable and unidimensional fashion scale.

The main objective of this research was to provide not only a unidimensional and homogeneous scale but also a validated fashion scale. Other studies also analyzed fashionrelated activities and behavioral dimensions [20,39,53,61]. They used distinct continuums rather than defined groups to reflect and segment markets. While a continuum in combination with Likert scales allows for parametric statistical procedures, it also provides more accurate results in contrast to grouping people into specific categories. However, none of these studies focused on fashion interest, and none of them validated their scale with a control group and focused on validating the questionnaire itself. Considering the long history of fashion scales, it was overdue actually to validate the fashion interest scale. Therefore, this study contributes to the knowledge of fashion interest scales by providing a validated scale.

This study also indicates that fashion interest depends on gender identity, with females having a higher fashion interest than males. This finding aligns with previous studies that determined that females have a significantly higher fashion trend sensitivity [20] and are more involved in fashion $[18,35]$. An exception is male fashion students, whose fashion interest is higher than their female colleagues. Bakewell, Mitchell [62] studied the fashion consciousness of male consumers from Generation Y. When the research was conducted, the generation cohort group $\mathrm{Y}$ was under 25 years old. They found that men recognize fashion and their relationship as either being or not being fashionable, with the former encompassing fashion consciousness, fashion knowledge, liking fashion, and consumption practices. Our study, however, could provide more detailed results because of the use of a multi-item continuous scale. The scale might explain why male students who study fashion might be more committed to fashion than their female counterparts.

$\mathrm{O}^{\prime}$ Cass [18] further reports that younger participants are more involved in fashion, and Lang, Armstrong [20] found that younger age correlates with fashion trend sensitivity. We can confirm that fashion interest is dependent on age and that the youngest age group exhibits the highest interest in fashion. Moreover, Birtwistle and Moore [63] claim that females aged 18-25 years are more interested in fashion and purchase more fashion garments than older people and go shopping more frequently. This finding aligns with our study because fashion students have a lower income than the random sample but go shopping for clothes more often, a finding that only can result from a continuous scale that allows 
analyzing interactions. More than a third of the students go shopping each week or every other week.

In line with [53] we could not find a correlation between fashion innovativeness and annual household income. Results from the Ontario sample show that people with an income between CAD 100,000-CAD 250,000 have about the same high fashion interest as fashion students. These results suggest that fashion needs to be cheap and affordable for younger customers or luxury for those who can afford it. Hence, fashion is split into luxury brands and fast fashion. The latter is described in the literature as low-cost clothing, which attracts young consumers and copies current luxury fashion trends [64]. The first is described to be particularly attractive for conspicuous consumption for consumers with higher societal status [7].

\section{Limitations and Further Research}

This paper provides a fashion scale to describe people's fashion interest better and accommodate their wants and needs. The sampling size looked only at the perspectives of a sample from Ontario, Canada, and at students enrolled at a fashion college in the same region. This scale has yet to be considered for other markets and territories. More research from additional areas such as China and India is needed to determine whether this scale is generalizable to other demographics. Furthermore, qualitative research conducted with various demographics would help to understand different markets' fashion interest and fashion consumption preferences.

This study validated the fashion interest scale with a control group. Still, a test-retest evaluation where the responses from individuals to the questionnaire remain relatively the same would further strengthen the reliability of this questionnaire [61]. A high internal validation ensures that responses are not random but instead reproduce the same results repeatedly, providing quality data that are stable and representative. On the other hand, people change their attitudes and behavior over time, and it would be helpful to determine the effect of these changes on fashion interest. For example, do fashion students maintain their fashion interest once they become older and work in the industry, or does it drop to the same level as from the random sample?

The purpose of this paper is not to evaluate or judge whether consumers are fashionable but to develop a tool to determine a person's fashion interest and to segment markets according to fashion interest and shopping behavior. Future research may explore this fashion scale's applicability as a market segmentation tool to different social and cultural groups and other behaviors and attitudes, such as accepting new business models, online shopping, or even environmental activities. Though online shopping has already been popular at the time of data gathering, it might be interesting to analyze the impact of fashion interest on online shopping [65]. A study by Park and Sullivan [66], for instance, found that consumers with higher fashion interest require higher fashion content from websites. Hence, the developed scale might be used to evaluate this finding. Moreover, the scale can be used to distinguish between consumption because of fashion interest and conspicuous consumption [5-7]. Both drivers of consumption might increase unsustainable textile consumption. In addition, the scale can be used to conduct research about the attractiveness of secondhand and vintage markets $[14,15,19]$. These markets might be attractive for consumers with high fashion interest and contribute to a more sustainable fashion consumption. Finally, future research might analyze differences in fashion interest between types of clothes. Though the fashion interest scale contains questions about how fashionable the clothes are, an analysis of different types of clothes or accessories might be interesting.

\section{Conclusions}

The validated scale can reflect the entire spectrum of fashion interest ranging from highly interested to the non-interested fashion consumer, or better clothing consumer to emphasize that not all clothing consumed is fashion. Based on the fashion index, the 
differences among customers can be used as a segmentation criterion for markets and relate fashion interest with other attitudes and behaviours. Researchers in sustainable fashion claim that transforming the fashion industry requires determining customers' motives for using and buying clothes, the size of the different market segments according to their fashion wants and needs, and the opportunities for new business models to meet their needs [16], p. 30. This study can help determine the different market interests according to their fashion wants and needs by providing a tool to segment the markets.

Author Contributions: Conceptualization, S.W.; methodology, S.W. and O.W.; validation, S.W and O.W.; formal analysis, S.W.; investigation, S.W.; resources, S.W.; data curation, S.W. and O.W.; writing - original draft preparation, S.W.; writing—review and editing, S.W. and O.W.; visualization, S.W. and O.W. All authors have read and agreed to the published version of the manuscript.

Funding: This research received no external funding.

Institutional Review Board Statement: The study was conducted in accordance with the Declaration of Helsinki, and approved by the Seneca Research Ethics Board (16-31, January 3, 20171).

Informed Consent Statement: Informed consent was obtained from all subjects involved in the study.

Data Availability Statement: The data are available from the corresponding author.

Conflicts of Interest: The authors declare no conflict of interest.

\section{References}

1. Fashion United. Global Fashion Industry Statistics. Data 2020. Available online: https://fashionunited.com/global-fashionindustry-statistics / (accessed on 15 July 2020).

2. Imran, A.; Berg, A.; Hedrich, S.; Leon, J.; Young, R. The State of Fashion 2017; McKinsey \& Company: London, UK, 2017; 49p.

3. Wahnbaeck, C.; Roloff, L. After the Binge, the Hangover: Insights into the Minds of Clothing Consumers; Greenpeace: Hamburg, Germany, 2017.

4. Gwozdz, W.; Nielsen, K.S.; Müller, T. An environmental perspective on clothing consumption: Consumer segments and their behavioral patterns. Sustainability 2017, 9, 762. [CrossRef]

5. Bagwell, L.S.; Bernheim, B.D. Veblen effects in a theory of conspicuous consumption. Am. Econ. Rev. 1996, 86, 349-373.

6. O'Cass, A.; McEwen, H. Exploring consumer status and conspicuous consumption. J. Consum. Behav. 2004, 4, 25-39. [CrossRef]

7. Souiden, N.; M'Saad, B.; Pons, F. A Cross-Cultural Analysis of Consumers' Conspicuous Consumption of Branded Fashion Accessories. J. Int. Consum. Mark. 2011, 23, 329-343. [CrossRef]

8. Loschek, I. When Clothes Become Fashion: Design and Innovation Systems; Berg: Oxford, UK, 2009.

9. Fletcher, K. Sustainable Fashion and Textiles: Design Journeys; Routledge: Oxfordshire, UK, 2013.

10. Craik, J. Fashion: The Key Concepts; Berg Publishers: Oxford, UK, 2009.

11. Keiser, S.J.; Garner, M.B. Beyond Design, 3rd ed.; Fairchild Publications, Inc.: New York, NY, USA, 2012.

12. Wilson, E. Adorned in Dreams: Fashion and Modernity; Rutgers University Press: New Jersey, NJ, USA, 2003.

13. Ajzen, I. The Theory of Planned Behavior. Organ. Behav. Hum. Decis. Processes 1991, 50, 179-211. [CrossRef]

14. Yang, S.; Song, Y.; Tong, S. Sustainable Retailing in the Fashion Industry: A Systematic Literature Review. Sustainability 2017, 9, 1266. [CrossRef]

15. Turunen, L.L.M.; Leipämaa-Leskinen, H. Pre-loved luxury: Identifying the meanings of second-hand luxury possessions. J. Prod. Brand Manag. 2015, 24, 57-65. [CrossRef]

16. Ellen MacArthur Foundation. A-New-Textiles-Economy, Redesigning Fashion's Future; Ellen MacArthur Foundation: Cowes, UK, 2008.

17. Weber, S. How Consumers Manage Textile Waste. Master's Thesis, University of Waterloo, Waterloo, ON, USA, 2015.

18. O'Cass, A. Fashion clothing consumption: Antecedents and consequences of fashion clothing involvement. Eur. J. Mark. 2004, 38, 869-882. [CrossRef]

19. Cervellon, M.C.; Carey, L.; Harms, T. Something old, something used. Int. J. Retail. Distrib. Manag. 2012, 40, 956-974. [CrossRef]

20. Lang, C.; Armstrong, C.M.; Brannon, L.A. Drivers of clothing disposal in the US: An exploration of the role of personal attributes and behaviours in frequent disposal. Int. J. Consum. Stud. 2013, 37, 706-714. [CrossRef]

21. Gam, H.J. Are fashion-conscious consumers more likely to adopt eco-friendly clothing? J. Fash. Mark. Manag. 2011, 15, 178-193.

22. Boateng, G.O.; Neilands, T.B.; Frongillo, E.A.; Melgar-Quiñonez, H.R.; Young, S.L. Best Practices for Developing and Validating Scales for Health, Social, and Behavioral Research: A Primer. Front. Public Health 2018, 6, 149. [CrossRef]

23. Kaiser, S.B. The Social Psychology of Clothing: Symbolic Appearances in Context; Fairchild Books: London, UK, 1997.

24. Workman, J.E.; Caldwell, L.F. Centrality of visual product aesthetics, tactile and uniqueness needs of fashion consumers. Int. J. Consum. Stud. 2007, 31, 589-596. [CrossRef]

25. Von Busch, O. The Game of Fashion and Lookbook; Thames and Hudson: New York, NY, USA, 2012; pp. 16-19.

26. Frings, G.S. Fashion: From Concept to Consumer; Prentice Hall: Hoboken, NJ, USA, 2008. 
27. Baumgartner, J. You Are What You Wear_What Your Clothes Reveal about You; Da Capo Lifelong Books: Philadelphia, PA, USA, 2012.

28. Corner, F. Why Fashion Matters; Thames \& Hudson: London, UK, 2014.

29. Wu, J. Chinese Fashion from Mao to Now; Berg: New York, NY, USA, 2009.

30. González, A.M.; Bovone, L. Identities Through Fashion: A Multidisciplinary Approach; Berg: Oxford, UK, 2012.

31. Workman, J.E.; Kidd, L.K. Use of the need for uniqueness scale to characterize fashion consumer groups. Cloth. Text. Res. J. 2000, 18, 227-236. [CrossRef]

32. Rogers, E.M. A prospective and retrospective look at the diffusion model. J. Health Commun. 2004, 9, 13-19. [CrossRef]

33. Summers, J.O. The identity of women's clothing fashion opinion leaders. J. Mark. Res. 1970, 7, 178-185. [CrossRef]

34. Lasch, C. The Culture of Narcissism; Abacus: London, UK, 1980; 426p.

35. Tigert, D.J.; Ring, L.J.; King, C.W. Fashion involvement and buying behavior: A methodological study. Adv. Consum. Res. 1976, 3, 46-52.

36. Ju, N.; Lee, K.-H. Consumer resistance to innovation: Smart clothing. Fash. Text. 2020, 7, 21. [CrossRef]

37. Law, K.M.; Zhang, Z.M.; Leung, C.S. Fashion change and fashion consumption: The chaotic perspective. J. Fash. Mark. Manag. Int. J. 2004, 8, 362-374.

38. Robert, D.; John, R. Store atmosphere: An environmental psychology approach. J. Retail. 1982, 58, 34-57.

39. Strategic Business Insights. Understanding US Consumers; Strategic Business Insights: Menlo Park, CA, USA, 2013.

40. Guthrie, K.M.; Regni, R.J. Perry's Department Store; Fairchild Publications: New York, NY, USA, 2006.

41. Rath, P.M.; Petrizzi, R.; Gill, P. Marketing Fashion: A Global Perspective; Fairchild Publications: New York, NY, USA, 2012.

42. Cahill, D.J.; Weinstein, A. Lifestyle Market Segmentation; Routledge: Oxfordshire, UK, 2006.

43. Dhurup, M. The effects of fashion interest, product novelty and product quality on brand consciousness and brand loyalty in fashion apparel purchase. Mediterr. J. Soc. Sci. 2014, 5, 32. [CrossRef]

44. Bhatia, V. Impact of fashion interest, materialism and internet addiction on e-compulsive buying behaviour of apparel. J. Glob. Fash. Mark. 2019, 10, 66-80. [CrossRef]

45. Gutman, J.; Mills, M.K. Fashion life-style, self-concept, shopping orientation, and store patronage-an integrative analysis. J. Retail $1982,58,64-86$.

46. Park, H.J.; Burns, L.D. Fashion orientation, credit card use, and compulsive buying. J. Consum. Mark. 2005, 22, 135-141. [CrossRef]

47. Matthews, D.; Rothenberg, L. An assessment of organic apparel, environmental beliefs and consumer preferences via fashion innovativeness. Int. J. Consum. Stud. 2017, 41, 526-533. [CrossRef]

48. Kim, S.-H. The mediate effect of gender on the differences of consumers grouped by the level of fashion interest. J. Korean Soc. Costume 2005, 55, 33-46.

49. Weber, S.; Lynes, J.; Young, S.B. Fashion interest as a driver for consumer textile waste management: Reuse, recycle or disposal. Int. J. Consum. Stud. 2017, 41, 207-215. [CrossRef]

50. Joo Park, E.; Kim, E.Y.; Forney, J.C. A structural model of fashion-oriented impulse buying behavior. J. Fash. Mark. Manag. Int. J. 2006, 10, 433-446. [CrossRef]

51. Browne, B.A.; Kaldenberg, D.O. Conceptualizing self-monitoring: Links to materialism and product involvement. J. Consum. Mark. 1997, 14, 31-44. [CrossRef]

52. Weber, S. How Consumers Manage Textile Waste. In School of Environment and Resource Sustainability; University of Waterloo: Waterloo, ON, Canada, 2015; p. 156.

53. Morgan, L.R.; Birtwistle, G. An investigation of young fashion consumers' disposal habits. Int. J. Consum. Stud. 2009, 33, 190-198. [CrossRef]

54. Wold, S.; Esbensen, K.; Geladi, P. Principal component analysis. Chemom. Intell. Lab. Syst. 1987, 2, 37-52. [CrossRef]

55. Cronbach, L.J. Coefficient alpha and the internal structure of tests. Psychometrika 1951, 16, 297-334. [CrossRef]

56. Thurstone, L.L. Multiple factor analysis. Psychol. Rev. 1931, 38, 406. [CrossRef]

57. Statistics Canada. Focus on Geography Series. 2011. Available online: https://www12.statcan.gc.ca/census-recensement/2011 /as-sa/fogs-spg/Index-eng.cfm (accessed on 1 August 2021).

58. Statistics Canada. Individuals by Total Income Level, by Province and Territory (Ontario). 2014. Available online: https: //www150.statcan.gc.ca/t1/tbl1/en/tv.action?pid=1110023901 (accessed on 1 August 2021).

59. Noh, M.; Li, M.; Martin, K.; Purpura, J. College men's fashion: Clothing preference, identity, and avoidance. Fash. Text. 2015, 2, 27. [CrossRef]

60. Lang, C.; Armstrong, C.M.J. Fashion leadership and intention toward clothing product-service retail models. J. Fash. Mark. Manag. Int. J. 2018, 22, 571-587. [CrossRef]

61. Tsang, S.; Royse, C.F.; Terkawi, A.S. Guidelines for developing, translating, and validating a questionnaire in perioperative and pain medicine. Saudi J. Anaesth. 2017, 11, S80. [CrossRef]

62. Bakewell, C.; Mitchell, V.W.; Rothwell, M. UK Generation Y male fashion consciousness. J. Fash. Mark. Manag. Int. J. 2006, 10, 169-180. [CrossRef]

63. Birtwistle, G.; Moore, C.M. Fashion clothing-where does it all end up? Int. J. Retail. Distrib. Manag. 2007, 35, 210-216. [CrossRef]

64. Joy, A.; Sherry, J.F., Jr.; Venkatesh, A.; Wang, J.; Chan, R. Fast fashion, sustainability, and the ethical appeal of luxury brands. Fash. Theory 2012, 16, 273-295. [CrossRef] 
65. McCormick, H.; Livett, C. Analysing the influence of the presentation of fashion garments on young consumers' online behaviour. J. Fash. Mark. Manag. Int. J. 2012, 16, 21-41. [CrossRef]

66. Park, H.H.; Sullivan, P. Market segmentation with respect to university students' clothing benefits sought: Shopping orientation, clothing attribute evaluation, and brand repatronage. Int. J. Retail. Distrib. Manag. 2009, 37, 182-201. [CrossRef] 